\title{
Blind Assist System
}

\author{
Deepak Gaikwad $^{1}$, Chaitalee Baje ${ }^{2}$, Vaishnavi Kapale ${ }^{3}$, Tejas Ladage ${ }^{4}$ \\ Assistant Professor, E\&TC Department, NBN Sinhgad School of Engineering, Pune \\ Student,E\&TC Department, NBN Sinhgad School of Engineering, Pune
}

\begin{abstract}
We are able to see the beauty of nature, things which happen in day-to-day life with the help of our eyes. But there are some people who are unableto experience these things. Many difficulties are seen by them in daily life. It is very challenging issue even for doing small tasks. So there is always need of helping hands for such visually impaired person. The blind assist system will help the blind person by providing more convenient means of life. In this paper we propose a light weight, inexpensive as well as user friendly system using infrared technology. This system will helpto live independently and happily without facing many difficulties. Thus this system will lower their challenging issues and will lead to social service towards visually impaired person.
\end{abstract}

Keywords: Infra-red Sensors, Microcontroller, Buzzer, GPS.

\section{INTRODUCTION}

Near about 37 million people across the globe are blind whereas over 15 million are from India. People with visual disabilities are often dependent mainly on humans, trained dogs, or special electronic devices as support systems for making their decisions. Surviving devices, the objects that are at a sudden depth or obstacles above waist level or stairs create considerable risks. Thus we were motivated to develop a smart system to overcome these limitations. So inshortwe are going to undertake this goal by adding infrared sensors. These IRsensors will help in providing information about the environment to the user. This will be carried out through audio feedback since blind user is unable to visualize surrounding world. The main component of this system is the GPS module which is used to find the current location of blind user. The stick finder module using buzzer will help in searching his/her stick wherever he had forgotten or left over. Other devices will help are used to guide particular path where he/she has to go for. Obstacle detection will help to protect him from hitting from that particular obstacle.The infrared sensors are used in this paper because they are small, cheap, and have low power consumption.Such devices help in producing beams of ultrasound, infrared or laser light.

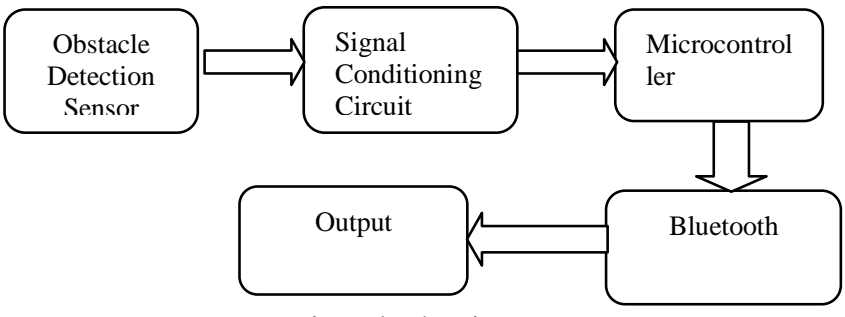

Fig. Block Diagram

The live monitoring module using GPS is included to provide the blind persons safety operation. Concerned person can live monitor the blind user using this module and can obtain the current location of blind user via SMS.If blind user forgets it's stick anywhere in the indoor location so he can find his stick using stick finder. Here blind user has to give speech input to android device via some fixed text which is fitted in device, and the buzzer mounted on stick starts. So via this sound tracking stick can be found. For the safety at night time a light sensors are used. As the intensity of light falls down the LED glows giving indication about blind user. So in this way the proposed system is going to work.

\section{PROPOSED METHODOLOGY}

\section{METHODOLOGY}

The summary of the system as shown in this figure gives the detailed clarification of each block is explained below:

Working of the system starts with the obstacle detection using IR sensors. The IR sensors are used to detect obstacles in three directions which arefront, left and right. Using sensor circuitry it detects obstacle. Then it is provided this as input to microcontroller. This controller is connected to android device via Bluetooth, which produces speech output according to microcontroller instructions.

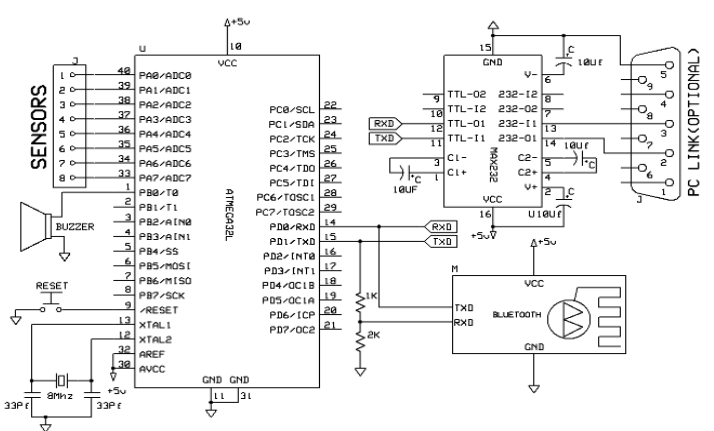

Fig. Circuit Diagram 


\section{A. Microcontroller:}

The ATmega32 is a low-power CMOS 8-bit microcontroller based on the AVR enhanced RISC architecture. By executing powerful instructions in a single clock cycle, the ATmega32 achieves throughputs approaching 1 MIPS per $\mathrm{MHz}$ allowing the system designer to optimize power consumption versus processing speed.

\section{B. IR SENSOR:}

An IR sensor is basically a device which consists of a pair of an IR LED and phototransistors which are collectively called a photocoupler or an opto-coupler. The IR LED emits IR radiation, receptionand/or intensity of reception.

Every sensor in this world has three terminals:Vcc - to power up the sensor.GND - to provide a fixed negative reference, Output - analog output of the sensor

\section{BLUETOOTH:}

HC-05 module is an easy to use Bluetooth SPP (Serial Port Protocol) module, designed for transparent wireless serial connection setup. Serial port Bluetooth module is fully qualified Bluetooth V2.0+EDR (Enhanced Data Rate) 3Mbps Modulation with complete $2.4 \mathrm{GHz}$ radio transceiver and baseband. It uses CSR Bluecore 04External single chip Bluetooth system with CMOS technology and with AFH (Adaptive Frequency Hopping Feature). It has the footprint as small as $12.7 \mathrm{mmx} 27 \mathrm{~mm}$.

\section{LDR:}

A photo resistor or light-dependent resistor (LDR) or photocell is a light-controlled variable resistor. The resistance of a photo resistor decreases with increasing incident light intensity; in other words, it exhibits photo conductivity.

\section{E. LED:}

Light-emitting diode (LED) is a semiconductor light source. LEDs are used as indicator lamps in many devices, and are increasingly used for lighting. When a lightemitting diode is forward biased (switched on), electrons are able to recombine with holes within the device, releasing energy in the form of photons.

\section{F.BUZZER:}

A buzzer or beeper is an audio signalling device, which may be mechanical, electromechanical, or piezoelectric. Typical uses of buzzers and beepers include alarm devices, timers and confirmation of user input such as a mouse click or keystroke.

\section{G. GPS MODULE:}

New improved GPS Module with built-in antenna and memory back-up for OEM and hobbyists projects. This unit features low power consumption, high sensitivity. The unit is ideal for navigation systems, distance measurements, vehicle monitoring and recording, boating direction and location, together with hiking and cross country exploring.

\section{HARDWARE DIAGRAM}

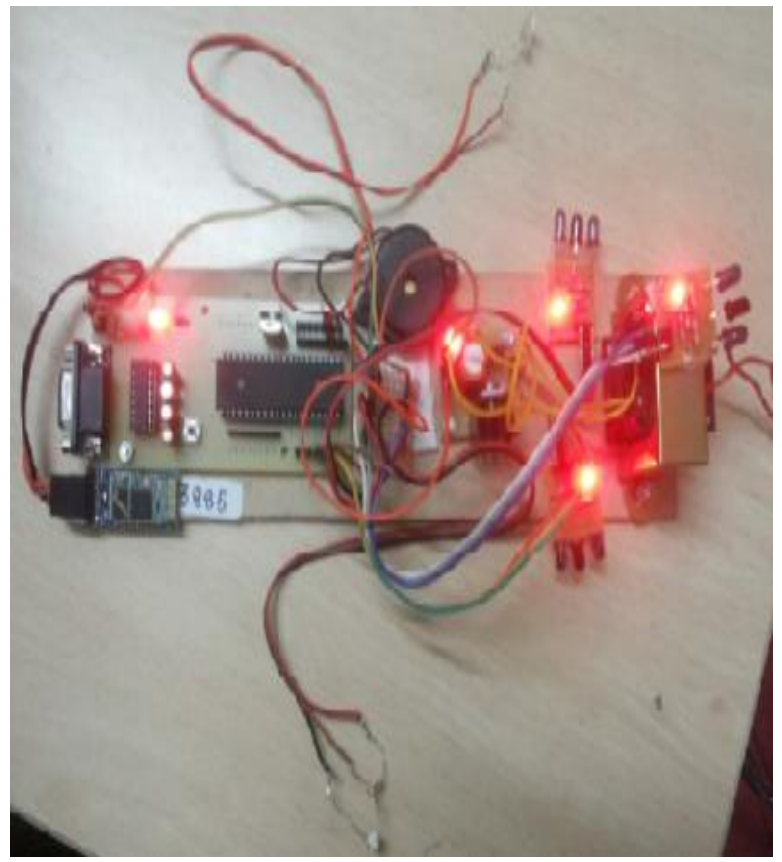

Fig. Hardware Diagram

\section{ADVANTAGES}

This system reduces the dependency on other family members. It is simple, and easy to handle guidance system. With the help of blind assist system, reduce minor collision, and increase safety. Audio feedback short prerecorded messages informing the user about the obstacles can be played. Vibration feedback are provided.Detects obstacle and alerts the blind person through vibration alert and speech output.

\section{DISADVANTAGES}

If Bluetooth connection is lost, we have to reconnect it manually.

\section{FUTURE SCOPE}

Instead of using stick, we can build our system on wrist, etc. Also navigation can be done in future scope in order to make this system considering additional parameters. Connecting with the concern people can be done via calling system where the contact numbers can be saved in database and will help in contacting that particular concern person when the blind user will be needing help.

\section{CONCLUSION}

In this paper, a solution is proposed to help visually impaired person to travel safely. With the help of blind assist system, people can advance travel speed, diminish trivial collision, do not lose their way, and increase safety a compare to unaided equipment's. 


\section{REFERENCES}

1. Shashank Chaurasia and K.V.N. Kavitha , "An Electronic Walking Stick for Blinds", ICICES2014 - S.A.Engineering College, Chennai, Tamil Nadu, India, ISBN No.978-1-4799-38346/14@2014 IEEE

2. Prasun Shrivastava, Akash Singh, Praveen Anand, V Sagar , "Medico Stick :An Ease to Blind \& Deaf "IEEE Sponsored $2^{\text {nd }}$ International Conference On Electronics And Communication System (ICECS 2015)"

3. Ayat A. Nada, Mahmoud A. Fakhr, Ahmed F. Seddik," Assistive Infrared Sensor Based Smart Stick for Blind People" Science and Information Conference 2015 July 28-30, 2015.

4. Abhishek Bhokare, Amruta Amberkar, Anvesh Gawde, Pratham Kale and Abhijeet Pasi. "Ultrasonic Blind Walking Stick", International Journal on Recent and Innovation Trends in Computing and Communication Volume: 4 Issue: 1 ISSN: 2321$816962-65$

5. G.Prasanthi and P.Tejaswitha, "Sensor Assisted Stick for the Blind People", Transactions on Engineering and Sciences ISSN: 23471964 (Online) 2347-1875 (Print) Vol.3, Issue 1, January 2015.

6. Rohit Sheth, Surabhi Rajandekar, Shalaka Laddha and Rahul Chaudhari, "Smart White Cane - An Elegant and Economic Walking Aid",American Journal of Engineering Research (AJER)eISSN: 2320-0847 p-ISSN: 2320-0936 Volume-03, Issue-10, pp-8489.

7. Ms. Ragini Singh, Arjun Succena and Neha Singh, "PIR Based Blind Walking Stick", International Journal of Computer Science and Mobile Computing, Ragini Singh et al, International Journal of Computer Science and Mobile Computing, Vol.5 Issue.4, April2016, pg. 486-490.

8. Prof.Bhavna Ambudkar, Pankaj Patil, Kunal Bonage, and Bhimsen Gire ,"Voice Navigation Stick for Blind", International Journal of Advance Foundation And Research In Science \& Engineering (IJAFRSE) Volume 1, Issue 9, February 2015. Impact Factor: 1.036, Science Central Value: 26.54.

9. G.Gayathri, M.Vishnupriya, R.Nandhini, Ms.M.Banupriya,"Smart Walking Stick For Visually Impaired",International Journal Of Engineering And Computer Science ISSN:2319-7242 Volume 3 Issue 3 March, 2014 Page No. 4057-4061.

10. Manoj Badoni and Sunil Semwal, "Discrete Distance and Water Pit Indicator using AVR ATmega8 in Electronic Travel Aid for Blind", International Journal of Disaster Recovery and Business Continuity Vol. 2, November, 2011. 